\title{
Vocabulary, metacognitive knowledge and task orientation as predictors of narrative picture book comprehension: from preschool to grade 3
}

\author{
Janne Lepola ${ }^{1} \cdot$ Anu Kajamies $^{1} \cdot$ Eero Laakkonen $^{1} \cdot$ Pekka Niemi $^{2}$
}

Published online: 3 January 2020

(c) The Author(s) 2020

\begin{abstract}
This is a study of early picture book comprehension, its determinants and later development through primary school. More specifically, picture book comprehension was analyzed longitudinally from age 5 to age 9, delineating the unique contributions of vocabulary, metacognitive knowledge and task orientation to the initial level as well as to the growth of comprehension. A total of 90 Finnish-speaking children participated in the study. The children's narrative picture book comprehension was assessed at age 5, age 6 and age 9. Vocabulary, metacognitive knowledge and task orientation were evaluated at age 5. Latent growth curve modeling showed a pattern of decreasing achievement gaps in narrative picture book comprehension. Vocabulary and metacognitive knowledge uniquely contributed to the concurrent level of narrative picture book comprehension. The results further showed that metacognitive knowledge and task orientation were positive and statistically significant predictors of the growth of picture book comprehension over and above the initial level of narrative picture book comprehension. These findings add to our knowledge about the development of inter-individual differences in narrative picture book comprehension and the roles of vocabulary, metacognitive knowledge and task orientation in it. They also suggest a novel way to assess the narrative comprehension potential among students with compromised working memory or decoding ability.
\end{abstract}

Keywords Narrative picture book comprehension · Vocabulary · Metacognitive knowledge · Task orientation · Children · Latent growth curve modeling · Longitudinal study

Janne Lepola

janlep@utu.fi

1 Department of Teacher Education, University of Turku, Assistentinkatu 5, 20014 Turku, Finland

2 Department of Psychology, University of Turku, Turku, Finland 


\section{Introduction}

Picture books are an essential part of the textual environment in the home as well as in preschool. Many picture books have a narrative structure that is, they incorporate a particular setting and characters involved in goal-directed actions. Pictorial stories provide opportunities for children to practice their comprehension skills independent of decoding. Consequently, children learn to encode the individual events of the narrative and make inferences regarding those events that are connected to each other. These abilities develop through early childhood and are related to later reading comprehension (Kendeou, van den Broek, White, \& Lynch, 2009; Lepola, Lynch, Kiuru, Laakkonen, \& Niemi, 2016; Oakhill \& Cain, 2012).

In the present study, we examine the development of prereaders' narrative picture book comprehension through a wordless picture book task. The task required the children to view a series of pictures by themselves, not being narrated by an adult, and to construct a meaning-based representation of the story. We ask a hitherto unexplored question that is, if individual growth in narrative picture book comprehension can be predicted by variables that have been found valid in predicting reading comprehension, namely vocabulary (e.g., Perfetti \& Stafura, 2014), metacognitive knowledge (Annevirta, Laakkonen, Kinnunen, \& Vauras, 2007; Pressley \& Gaskins, 2006) and task-oriented behavior (Hirvonen, Georgiou, Lerkkanen, Aunola, \& Nurmi, 2010; Lehtinen, Vauras, Salonen, Olkinuora, \& Kinnunen, 1995; Lepola et al. 2016). Drawing on the theoretical considerations of Paris and Paris (2003) and text comprehension models (Perfetti, Landi \& Oakhill, 2005; Verhoeven \& Perfetti, 2008), we maintain that regardless of medium, similar comprehension processes are deployed when children study a pictorial narrative independently, listen to a narrative or, at later age, read one (Kendeou, Bohn-Gettler, White, \& van den Broek, 2008; Kim, 2016a).

\section{Narrative picture book comprehension}

Like text comprehension, comprehension of a wordless picture book is theorized to take place on different levels that is, surface (picture), text (narrative) and situation model (e.g., Kintsch \& Rawson, 2005). Because the meaning of these narratives is carried by visual images only, children must actively encode and elaborate the meanings of individual pictures. This may involve identifying and naming individual objects, characters and actions represented in the picture. On the other hand, to achieve a narrative representation, the child has to construct and integrate meanings across pictures by focusing on relevant as well as suppressing irrelevant information. In other words, they must "read" pictures strategically (Paris \& Paris, 2003). The child's ability to use story grammar categories (e.g., initiating event, problem, outcome) is essential to building and later recalling narrative representations. Moreover, narrative comprehension requires inference making to understand explicit and implicit information in the story as well as other higher-level cognitive skills such as monitoring ongoing comprehension (Florit, Roch, \& Levorato, 2011; Silva \& Cain, 2015; Tompkins, Guo, \& Justice, 2013). 
To construct a situation model on the basis of a pictorial narrative, the child must make further inferences to their background knowledge as well as engage in higherlevel processes such as discerning a theme of the story. What is more, extracting meaning from pictures without any verbal cues requires focus on the task and effortful engagement (Arizpe, 2013; Chaparro-Moreno, Reali, \& Maldonado-Carreno, 2017). The ability to find words for explicit and implicit information in pictures taxes vocabulary (Silva \& Cain, 2015). Forming a mental model on the basis of a wordless picture book is certainly complex and may well require active metacognitive knowledge of how various cognitive skills such as memory, learning and understanding affect comprehension of stories. The perspective outlined here is in line with the findings of Strasser and del Rio (2013) showing that a broad set of cognitive skills, including attention, vocabulary, inferences and comprehension monitoring play a role in narrative picture book comprehension.

Furthermore, as Feldman, Bruner, Renderer and Spitzer (1990) have argued, narrative story comprehension can be viewed as the ability to integrate information from two landscapes within a story. The landscape of action refers to the elements of story grammar, whereas the landscape of consciousness reflects what characters know, think or feel (Bruner, 1986). Cross-sectional evidence suggests that memory for story events is likely to precede the ability to make inferences about characters' motives and feelings (Khan, Gugiu, Justice, Bowles, Skibbe, \& Piasta, 2016; Paris and Paris, 2003, Table 12). With age, children also improve at identifying implicit information in the story (e.g., describing the character's goals and motives), connecting events in the story, and using their background knowledge to interpret story events that is, making inferences (Florit et al., 2011; Kendeou et al., 2008; Tompkins et al., 2013). These improvements have been observed by using different media, such as viewing a picture book (Lepola et al., 2016; Paris \& Paris, 2003) or listening to a story from an iPad (Filiatrault-Veilleux, Bouchard, Trudeau, \& Desmaraisd, 2016). Interestingly, despite the ubiquitous presence of picture books and their pivotal role in the development of preschoolers' narrative comprehension skills (Paris \& Paris, 2007; Zevenbergen \& Whitehurst, 2003), there is a lack of longitudinal studies of narrative picture book comprehension.

\section{Evaluation of the development of narrative comprehension skills}

Prereaders' narrative comprehension skills can be evaluated with three types of material: wordless picture books, picture books combined with listening, or listening only. Several studies have utilized a pictorial story with listening to an adult or an audiovisual story (Filiatrault-Veilleux et al., 2016; Kendeou et al., 2009; Khan et al., 2016; Lynch, van den Broek, Kremer, Kendeou, White, \& Lorch, 2008; Storch $\&$ Whitehurst, 2002). There is also abundant research on narrative listening comprehension in which the children hear either a live or audio-recorded story and then their comprehension is evaluated (Annevirta et al., 2007; Dufva, Niemi, \& Voeten, 2001; Florit, Roch, Altoé, \& Levorato, 2009; Florit, Roch, \& Levorato, 2014; Kim, 2016a, b; LARRC, 2017; Torppa, Georgiou, Lerkkanen, Niemi, Poikkeus, \& Nurmi, 2016). Most of these studies also include a developmental aspect. 
In contrast, only a handful of studies have relied on picture books in which words are absent and the story is not read to the child (Lepola et al., 2012; Paris \& Paris, 2003; Silva \& Cain, 2015; Silva, Strasser, \& Cain, 2014; Strasser \& del Rio, 2013; Tompkins et al., 2013). Interestingly, of these relevant studies, only that of Paris and Paris (2003) asked how components of picture book comprehension improved over time. The authors deployed two samples, one from Grade 1 to Grade 2 and the other from Grade 2 to Grade 3. Significant progress was found in children's literal and inferential comprehension skills as well as their ability to retell the main story elements. However, the cross-sectional design of Paris and Paris (2003) did not allow them to study whether the initial achievement gaps increased, decreased or remained stable over the years (for more detail, see Pfost, Hattie, Dörfler, \& Artelt, 2014). Moreover, previous studies have not examined the role of other resources, such as vocabulary, metacognitive knowledge and task orientation in the growth of children's narrative picture book comprehension.

\section{Predicting the development of narrative picture book comprehension: vocabulary, metacognitive knowledge and task orientation}

Regarding the role of vocabulary, evidence suggests that knowledge of word meanings facilitates not only listening comprehension of beginning readers (Florit, Roch, Altoé, and Levorato, 2009; Potocki, Magnan, \& Ecalle, 2013), but it also plays a role in their literal and inferential picture book comprehension (Silva \& Cain, 2015; Strasser \& del Rio, 2013). Although vocabulary plays an important role in word-totext integration in reading (Perfetti \& Stafura, 2014), less is known about the contribution of vocabulary to the initial status and the growth of prereaders' narrative picture book comprehension.

According to the conceptualization by Flavell (1979), metacognitive knowledge refers to "knowledge or beliefs about what factors or variables act and interact in what ways to affect the course and outcome of cognitive enterprises. There are three major categories of these factors or variables_person, task, and strategy (p. 907)." In other words, metacognitive knowledge reflects the extent to which the child possess knowledge about person (i.e., age, experience), task (i.e., number of items, external distractor) and strategy (i.e., categorization, explanation, practicing) factors in cognitive processing. More concretely, awareness of these factors have been measured in tasks where the child is asked, first, to rate what is the best way to remember, understand and learn things, and then to explain his or her rating (Annevirta et al., 2007; Wellman, 1977). Metacognitive knowledge has shown to be associated with 6- to 10-year-old students' text comprehension evaluated through listening and reading (Annevirta et al., 2007; Leppänen, Aunola, Niemi, \& Nurmi, 2008; van Kraayenoord, Beinicke, Schlagmuller, \& Schneider, 2012), and the facilitating role of metacognitive knowledge among proficient readers is clear (Pressley \& Gaskins, 2006). Annevirta and Vauras (2001) as well as Marulis, Palincsar, Berhenke, and Whitebread (2016) have shown that preschool-aged children and kindergartners already have metacognitive knowledge (for a review of recent studies, see Marulis, Baker, \& Whitebread, 2020). Empirical findings also suggest that a high level of 
metacognitive knowledge from kindergarten to Grade 2 is linked to better self-regulatory skills such as self-guided speech and comprehension monitoring (Annevirta \& Vauras, 2006). Moreover, comprehension monitoring has been found to predict picture book comprehension among prereaders (Strasser \& del Rio, 2013). Thus, it is plausible that children's metacognitive knowledge can be reliably assessed already at age 5, and this early metacognitive knowledge is a potent predictor of the development of narrative picture book comprehension.

Individual differences in children's task-focusing behaviors are related to the acquisition of word reading skills (Manolitsis, Georgiou, Stephenson, \& Parrila, 2009; Morgan, \& Fuchs, 2007) and reading comprehension (Georgiou, Manolitsis, Zhang, Parrila, \& Nurmi, 2013; Hirvonen et al., 2010). In the present study, task orientation refers to the child's intrinsically motivated tendency to accept and engage in challenging aspects of a learning task given by the teacher. This kind of motivational and social tuning into the task is observed as approaching, exploring, and mastering behaviors. The present conceptualization of task orientation draws on older depictions of children's and adults' problem- and emotion-focused coping strategies (Lazarus, 1991), the nature of intrinsic motivation (Harter, 1981) and the distinction between mastery and helplessness orientations (Diener \& Dweck, 1978). Our approach to task orientation also includes aspects of executive skills such as attention control and planning (Conners, 2009; Sesma, Mahone, Levine, Eason, \& Cutting, 2009).

A recent longitudinal study by Lepola et al. (2016) showed that teacher-rated task orientation and children's oral language comprehension including vocabulary, listening comprehension and inference-making about a pictorial story were reciprocally related from age 4 to age 9 . In addition, Strasser and del Rio (2013) found that 4- to 7-year-old children's attention to a pictorial story (based on an examiner's evaluation of the participants' focus on instructions, on-task behavior and cooperation) was a unique predictor of wordless picture book comprehension. Like reading comprehension, pictorial comprehension demands resources to initiate, maintain and coordinate automatic and effortful processes. Therefore, it is important to study the relevance of task-oriented behaviors in the development of narrative picture book comprehension.

\section{Aims and hypotheses}

In the present study, we examined the development of children's narrative picture book comprehension (hereafter picture book comprehension) from the age of 5 through the age 6 to the age of 9 years. The study had three aims. First, by using Latent Growth Curve (LGM) modeling, we investigated individual variation in the level of picture book comprehension, its growth rate (e.g., linear), and the association between its initial level and growth factor (Annevirta et al., 2007; Aunola, Leskinen, Arvilommi, \& Nurmi, 2002; Muthén \& Khoo, 1998). Second, we used the LGM approach to examine the extent to which vocabulary, metacognitive knowledge and task-oriented behavior at age 5 (preschool) contributed to the children's initial level of picture book comprehension at age 5. Third, and most important, we 
asked whether vocabulary, metacognitive knowledge and task-oriented behavior at age 5 predicted subsequent changes in children's picture book comprehension.

Regarding individual differences in the initial level of picture book comprehension at the age of 5, we hypothesized that each variable would be associated with picture book comprehension, but vocabulary would be its strongest concurrent predictor. This assumption is based on the prominent role of vocabulary in picture book comprehension (Lepola et al., 2012; Strasser \& del Rio, 2013), listening comprehension (Silva \& Cain, 2015) and other higher-level comprehension skills such as inference-making, theory of mind, and comprehension monitoring (Kim, 2016a). Further, we assumed that vocabulary, metacognitive knowledge and task orientation would be unique predictors of the growth of picture book comprehension (Annevirta et al. 2007; Lepola et al., 2016). Because of the exploratory nature of the study, we did not formulate hypotheses about whether achievement gaps would be increasing, decreasing or remaining stable across age (cf. Pfost et al., 2014).

\section{Method}

\section{Participants}

Ninety Finnish-speaking children (50 girls and 40 boys) participated from preschool to Grade 3. Their mean age was 62.5 months when the study started. The same children had participated in a previous study (Lepola et al., 2012) in which 135 Finnish children were followed from preschool to kindergarten. In Grade 3, contact could be established with 118 families, and written consent was granted by 90 (76\%) of them for their child to participate in a further data collection. The attrition was, for the most part, due to families moving (for more detail, see Lepola et al., 2016). Initially, the participants were in 16 daycare centers located in socioeconomically varied districts in two towns with 176,000 and 14,500 inhabitants. In Grade 3, the 90 children were in 17 elementary schools (26 classrooms). Based on a questionnaire, $18 \%$ of the mothers had a master's degree, $53 \%$ had a BA or vocational college degree, $22 \%$ had vocational education or a high school diploma, and $7 \%$ had no vocational education. The average educational level of mothers was slightly above the mean of Finnish females between 25 and 49 years at the time the study started (Statistics Finland, 2007).

\section{Materials and procedure}

At Time 1 (age 5, preschool fall), Time 2 (age 6, kindergarten fall) and Time 3 (age 9 , Grade 3 spring) picture book comprehension skills were evaluated individually in one session lasting $30 \mathrm{~min}$. We also assessed metacognitive knowledge and vocabulary at Time 1 (from September to November). Children's verbal responses in all tasks were recorded by a MP3 player for later transcription and scoring. Task-oriented behavior was assessed by preschool teachers at Time 1 . 


\section{Vocabulary}

A word definition test was used to assess vocabulary knowledge at Time 1 . The test was an adaptation of the vocabulary test of the Finnish Wechsler Intelligence Scale for Children (WISC-III; Wechsler, 1999). Cronbach's alpha in this sample was .82.

\section{Wordless picture book comprehension}

We used the tasks and procedure developed by Paris and Paris (2003). The RobotBot-Bot picture book by Krahn (1979) was used at the ages of 5 and 6 years. The book tells the story of a family (a child, parents) whose new robot "housecleaner" goes wild after the child plays with the wires. We used an adapted version of the book with 18 pages with one black line drawing on each double page. In Grade 3, we used the picture book A Boy, a Dog and a Frog by Mayer (1967). The procedure in Grade 3 was the same as that in preschool and kindergarten. The experimenter instructed the child at each time point by saying "I will give you a picture book that is about a robot/a boy, a dog and a frog. Look at what is happening in this book. Look carefully at all the pictures, and as you look at the pictures, you may tell me whatever there is going on. Now, you can start." In the present study, we used a retelling task, and 10 prompted questions to evaluate children's narrative comprehension (for details, see Paris \& Paris, 2003).

Retell task After the child had viewed the picture book the experimenter took the book and the child was asked to retell as much as possible of the story. The transcribed retellings were scored according to the six narrative elements of story grammar (Mandler \& Johnson, 1977). One point each was given for phrases referring to information from each story element: characters, setting, initiating event, problem, solution and resolution. The maximum score was six. Two raters independently scored the 5-, 6- and 9-year-olds' retellings. The percent match by each element was calculated. Interrater agreement was $89 \%$ for Time $1,89 \%$ for Time 2 and $81 \%$ for Time 3 across the elements.

Prompted comprehension questions After the retelling task, the experimenter and the child went through the story together and the experimenter asked 10 comprehension questions about it. The first five questions were explicit in nature demanding the identification of and reasoning about the main narrative elements: characters, setting, initiating event, and problem as well as outcome resolution. The answers to the remaining five questions were not directly illustrated in pictures but required the child to make inferences about characters' feelings, causal relations, dialogues, predictions and the theme of the story. Each question, apart from the characters, setting and theme, was followed by the question: "Why/how did that happen?" The follow-up discussion aimed to differentiate the answers referring to picture-level and narrative-level information. 
Each question was scored on a scale of $0-2$ according to the criteria by Paris and Paris (2003). More points were given for a child's answer when s/he integrated information across pages and made connections among the events (e.g., initiating event-problem, problem-solution, outcome-feelings). Thus, 0 points referred to no answer or a wrong or inappropriate answer; 1 point was given for an answer describing a single picture in isolation, or in implicit questions referring only to the previous page or event; and 2 points were awarded for an answer including information from other events/pictures to construct the meaning of the particular event in the story (i.e., to get 2 points in implicit question, a child had to refer at least to two pictures or tell a more global meaning of the picture; for details, see Lepola et al., 2016, Appendix A). For example, in the implicit question asking why the family got the robot, 2 points were given for answers such as "because they don't need to do all the work by themselves" and "because it can then wash and take garbage out." One point was given for a response reflecting page-level information, such as "because no more clean up" or "because it can wash up," and 0 points for no answer or an inappropriate answer, such as "the child wanted to". Inter-rater reliability that is, the percentage agreement, was above $85 \%$ for every question with a mean of $91 \%$ for Time 1, 96\% for Time 2, and 94\% for Time 3 data. Composite scores were computed for all prompted questions. One experimenter showed a wrong page/picture to a subset of children while asking the initiating event question at Time 1. Therefore, we had to eliminate that question from the longitudinal data. Consequently, there were nine prompted comprehension questions. Cronbach's alphas for picture book comprehension, based on retell task, prompted explicit and prompted implicit questions, were .73 for Time 1, .75 for Time 2 and .70 for Time 3 . The retelling and the prompted questions scores were summed to get picture book comprehension composites which were used in latent growth curve modeling.

\section{Metacognitive knowledge}

Children's knowledge of factors influencing memory, comprehension and learning were assessed by a pictorial metacognitive knowledge test including nine tasks (Annevirta \& Vauras, 2001). In each task, the experimenter showed all three pictures to the child (line drawings) simultaneously describing verbally each picture in which a boy or a girl was asked to do something that is, to remember, to understand or to learn. First, the child was instructed to choose the best alternative that is, to point out the picture that depicted the best way or strategy to remember, learn or understand something. Second, after choosing the particular picture s/he was asked to verbally explain the reason for selecting this alternative (e.g., why in this picture did the girl/boy remember, understand or learn best?) (See Appendix for an example of memory task and scoring it).

The quality of explanation that is, the child's ability to verbally refer to memory, comprehension or learning involved in the selected picture, was used as a measure of metacognitive knowledge. The quality of explanation was scored on a five-point scale from 0 to 4 . The child got 0 points if s/he did not point or verbally refer to any out of the three pictures. One point was given if the child selected one of the pictures, but her/his explanation for selecting the picture was unclear or naïve or child 
said that s/he did not know. Picture selection, even when based on irrelevant or no reason, is seen as a reflection of young child's emerging metacognitive knowledge as opposed to no action at all (Salonen, Lepola, Vauras, Rauhanummi, Lehtinen, \& Kinnunen, 1994). Two points were given for less explicit reference to the person's memory, understanding and learning, for instance by referring to the distinct feature in the selected picture. Three points meant fairly adequate description of memory, understanding and learning that is, the child referring to both the distinctive feature in picture and also to memory, understanding or learning. Four points were given to even more explicit accounts (for more details, see Annevirta and Vauras, 2001, Table 1). The agreement between two independent raters was computed for $20 \%$ of the data. The interrater agreement ranged between 88 and $93 \%$ with a mean of $89 \%$.

\section{Task orientation}

Preschool teachers were asked to evaluate the behavior, attention, and emotional expressions of each participating child in their class. Teachers rated the children in the fall term of preschool (November). Each teacher was asked first to recall playlike and crafts situations and new task activities that the child was asked to perform by the teacher, and then rate the child's behavior using a 7-point Likert-type scale that ranged from "the behavior does not occur at all" to "the behavior occurs most of the time or always." The instructions underscored that the focus of assessment was not free-play or the child's cognitive-linguistic abilities but the way the child adapts to the task at hand given by an adult. In the present study, five items reflecting task orientation were used: (1) is able to concentrate on crafts and play-like tasks, (2) shows a desire to do more challenging things, and (3) wants to continue the tasks (asks if s/he can do more), (4) ponders alternatives and plans for what s/he does, (5) is able to continue his/her activity despite external disturbing factors. Cronbach's $\alpha$ was .81. This scale, apart from the last item, has been shown to measure children's task orientation from age 4 to age 9 (Lepola et al., 2016). The last item was included to obtain broader view of the child's task focusing and self-regulatory behavior.

\section{Results}

Descriptive statistics for the measures at Time 1, Time 2, and Time 3 are shown in Table 1 . The distributions of the scores for summed measures were analyzed by the Kolmogorov-Smirnov test. The test showed that the data for vocabulary $(p=.09)$ and task orientation variables $(p=.07)$ at Time 1 were normally distributed. Normality assumption was not met for metacognitive knowledge at Time 1 and picture book comprehension scores at Time 1 and Time $3(p<.01)$. Picture book comprehension scores at Time 2 were normally distributed. As Table 1 indicates, $10 \%$ of children scored 0 in retelling at Time 1 and 2, and 63\% of children scored 6 in retelling at Time 3.

To analyze developmental changes and gender differences in the means, we conducted a $3 \times 2$ (Time $\times$ Gender) ANOVA with repeated measures on picture book comprehension. An ANOVA with linear contrasts revealed a significant linear effect 
Table 1 Descriptive Statistics for Vocabulary, Metacognitive Knowledge, Task Orientation and Picture Book Comprehension Variables $(\mathrm{N}=90)$

\begin{tabular}{lrrrrrr}
\hline Variables & \multicolumn{1}{l}{ M } & SD & Range & Skewness & $\begin{array}{c}\text { \% scoring } \\
\text { at floor }\end{array}$ & $\begin{array}{c}\text { \% scoring } \\
\text { at ceiling }\end{array}$ \\
\hline Age (months) & & & & & & \\
Vocabulary knowledge, T1 $\left(64^{1}\right)$ & 10.74 & 4.86 & 22 & -.18 & 3 & 0 \\
Metacognitive knowledge, T1 (36) & 11.57 & 2.48 & 14 & .81 & 0 & 0 \\
Task orientation, T1 (7) & 4.44 & 1.21 & 4.80 & -.27 & 0 & 0 \\
Picture book comprehension, T1 (24) & 12.66 & 4.37 & 21 & -.59 & 1 & 0 \\
Retelling (6) & 2.93 & 1.80 & 6 & .09 & 10 & 11 \\
Prompted questions (18) & 9.72 & 3.23 & 16 & -.75 & 1 & 0 \\
Picture book comprehension, T2 (24) & 14.54 & 4.54 & 22 & -.52 & 0 & 0 \\
Retelling (6) & 3.09 & 1.94 & 6 & .004 & 10 & 14 \\
Prompted questions (18) & 11.46 & 3.26 & 16 & -.80 & 2 & 0 \\
Picture book comprehension, T3 (24) & 19.20 & 3.64 & 21 & -2.12 & 0 & 1 \\
Retelling (6) & 5.20 & 1.31 & 6 & -1.97 & 1 & 63 \\
Prompted questions (18) & 14.0 & 2.76 & 16 & -1.70 & 1 & 3 \\
\hline
\end{tabular}

$T 1$ preschool, at age 5; T2 kindergarten, at age 6; T3 Grade 3, at age 9-10

${ }^{1}$ Maximum value in test

of time in picture book comprehension, $\left(F[1,86]=163.89, p<.001\right.$, partial $\left.\eta^{2}=.34\right]$. No significant gender differences were found across time.

Before reporting results of the latent growth curve modeling, we describe concurrent and longitudinal correlations of the variables across the three time points. Table 2 shows that vocabulary and metacognitive knowledge were significantly related to concurrent picture book comprehension. Interestingly, task orientation at age 5 was more strongly related to picture book comprehension at Time $3(r=.43)$ as compared to the concurrent association between them $(r=.23)$. The autocorrelation of the picture book comprehension variables was strong from Time 1 to Time

Table 2 Correlations among Vocabulary, Metacognitive Knowledge, Task Orientation and Narrative Picture Book Comprehension Variables from Preschool to Grade 3

\begin{tabular}{|c|c|c|c|c|c|c|}
\hline & 1 & 2 & 3 & 4 & 5 & 6 \\
\hline \multicolumn{7}{|l|}{ 1. Age } \\
\hline 2. Vocabulary knowledge (T1) & $.28 * *$ & & & & & \\
\hline 3. Metacognitive knowledge (T1) & .15 & $.35 * *$ & & & & \\
\hline 4. Task orientation (T1) & $.26 * *$ & $.25^{*}$ & $.37 * * *$ & & & \\
\hline 5. NPB comprehension (T1) & $.24 *$ & $.48 * * *$ & $.45 * * *$ & .23 & & \\
\hline 6. NPB comprehension (T2) & $.31 * *$ & $.43 * * *$ & $.50 * * *$ & $.34 * *$ & $.69 * * *$ & \\
\hline 7. NPB comprehension (T3) & .05 & $.35 * *$ & $.42 * * *$ & $.43 * * *$ & $.34 * *$ & $.48 * * *$ \\
\hline
\end{tabular}

$N P B$ narrative picture book. $T 1$ preschool, at age 5, T2 kindergarten at age 6, T3 grade 3, at age 9

$* p<.05, * * p<.01, * * * p<.001$ 
2 (.69) and moderately strong from Time 2 to Time 3 (.48). Age was significantly related to vocabulary $(r=.28)$, task orientation $(r=.26)$ and picture book comprehension at Time $1(r=.24)$ and Time $2(r=.31)$.

\section{Latent growth curve analyses}

First, to analyze the growth in picture book comprehension across three time points and to understand the role of inter-individual differences in the initial level (i.e., intercept), a latent growth curve model was estimated in Mplus 7.11 (Muthén \& Muthén, 1998-2012). For the intercept factor, factor loadings of the observed variables were fixed to 1 for each measurement point. Prior to fitting the growth model, we visualized individual trajectories for all children (Fig. 1). The plots of individual trajectories in picture book comprehension suggested linear growth, and therefore the factor loadings were fixed to 0,1 and 4 . These loadings correspond to a linear time scale of the assessments (i.e., preschool, kindergarten and Grade 3). Because of the residual variance in picture book comprehension in time 3 (Grade 3) was negative, this parameter was fixed to 0 .

The results of LGC model 1 showed that the level and the linear growth components were stochastic. This means that the variances of level (16.130) and linear

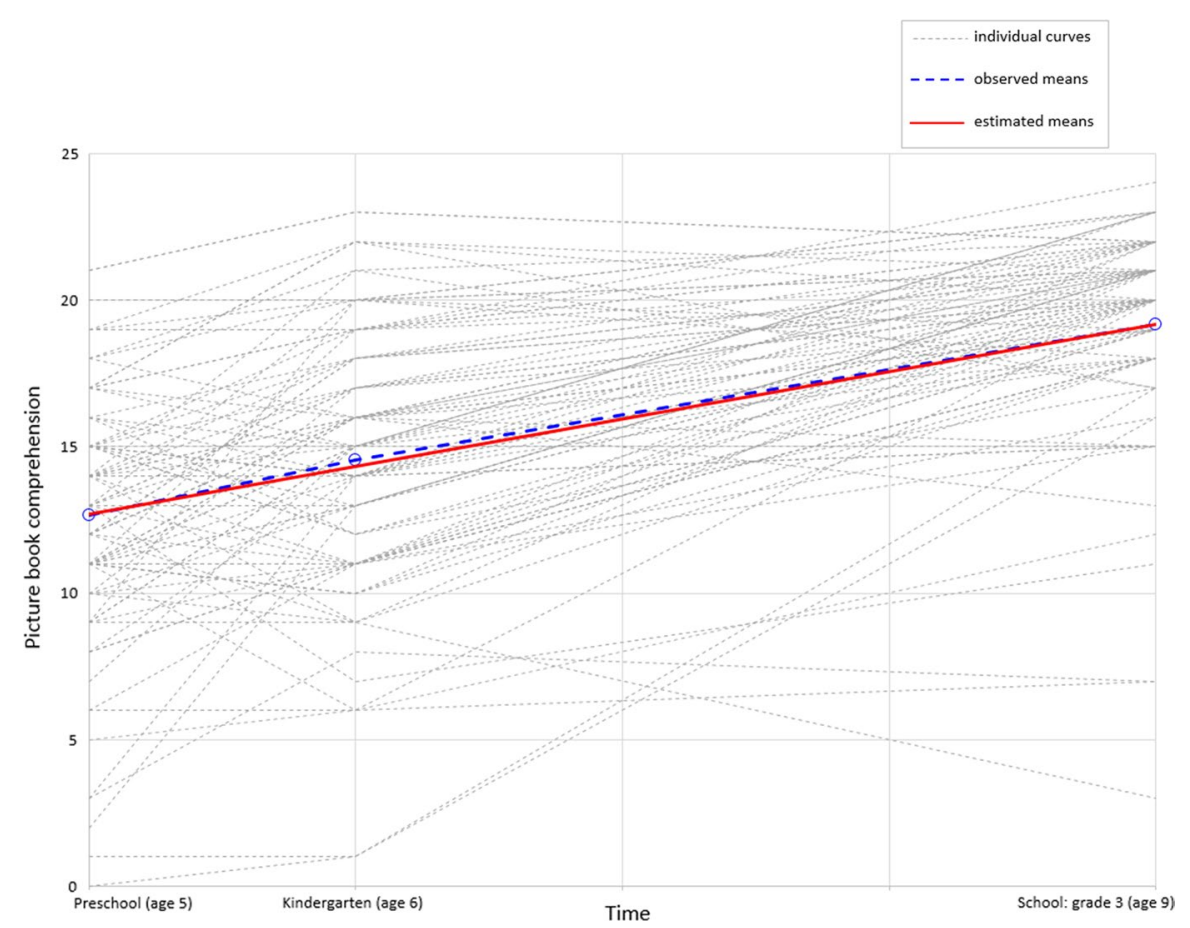

Fig. 1 Individual observed curves, observed means and estimated means based on the latent growth curve model 
Table 3 Latent growth models for narrative comprehension from preschool through Kindergarten to Grade 3 (Unstandardized Coefficients Reported; Standard Errors in Parenthesis)

Model 1 (linear)

Level (intercept) ${ }^{2}$

Metacognitive knowledge ${ }^{2}$

Vocabulary $^{2}$

Task orientation ${ }^{2}$

Variance components

Variation in intercept

Variation in linear trend

Residual variance for NC-t1

Residual variance for $\mathrm{NC}-\mathrm{t} 2$

Residual variance for NC-t3

Model fit
$1.601(.121)^{* * * *}$

$12.689(.453) * * *$

$12.696(.457) * * *$

$.687(.171)^{* * *}$

$.300(.089)^{* * *}$

$.053(.325)$

$2.126(.687)^{* * *}$

$-.233(.027)^{* * * *}$

$.092(.040)^{*}$

$.029(.016)$

$.211(.080)^{* *}$

$16.130(3.712)^{* * *}$
$1.153(.263)^{* * *}$
$2.824(2.071)$
$8.083(1.388)^{* * * *}$
.000
$\chi 2(2)=1.172, p=.556 ; \mathrm{RMSEA}=.00 ;$
$\mathrm{CFI}=1.00 ; \mathrm{TLI}=1.017 ; \mathrm{SRMR}=.013$

$8.728^{3}(2.947)^{* * * *}$

$.551^{3}(.140)^{* * * *}$

3.513 (1.981)

$7.685(1.245)^{* * *}$

.000

$\chi 2(5)=3.333, p=.648$;

RMSEA $=.00$;

$\mathrm{CFI}=1.00$; $\mathrm{TLI}=1.030$;

$\mathrm{SRMR}=.021$

${ }^{*} p<.05, * * p<.01, * * * p<.001$

${ }^{1}$ Predictors of level component (unstandardized estimates with standard errors in parenthesis)

${ }^{2}$ Predictors of growth rate component (unstandardized estimates with standard errors in parenthesis)

${ }^{3}$ Residual variance in level/growth rate factor

growth (1.153) components were statistically significant (Table 3). As model 1 shows, picture book comprehension was found to increase by 1.60 points in every consecutive time point. The results also showed that the path from the level to the linear growth of picture book comprehension was negative and statistically significant (- .623). This indicates, as also displayed in Fig. 1, that the lower the initial picture book comprehension was at age 5, the more improvement was observed from age 5 to age 9 . Thus, children with initial low picture book comprehension caught up with the children with initial high picture book comprehension.

Our second and third aims were to study the extent to which vocabulary, metacognitive knowledge and task orientation assessed at Time 1 (age 5), would each contribute to the initial level of picture book comprehension as well as predict the growth in picture book comprehension. To address this, a second latent growth curve model with initial level (i.e., intercept), linear growth component (i.e., trend) and the four predictors were constructed. It is important to note that we also controlled 
for the initial level. Thus, we examined whether the rate of change in picture book comprehension is a function of initial level and the predictors (see, e.g., Viljaranta et al., 2015; Wang \& Wang, 2012, p. 153). This was done because model 1 showed that initial level is a strong determinant of the subsequent growth of picture book comprehension. Age was not included in model 2 because it did not contribute significantly either to the initial level or to the growth of picture book comprehension in model 1.

As Table 3 shows, the fit of model 2 to the data was good. The results of model 2 show that metacognitive knowledge and vocabulary significantly contributed to the initial level of picture book comprehension at age 5. As can be further seen from Table 3 and Fig. 2, the pattern of predictors changed somewhat for the growth rate component. When the initial level of picture book comprehension was controlled for, task orientation and metacognitive knowledge turned out to be statistically significant predictors of the growth of picture book comprehension. Thus, vocabulary was not a significant predictor of the growth of narrative comprehension in the presence of metacognitive knowledge and task orientation. Model $2\left(\chi^{2}(5)=3.333\right.$, $p=.648 ; \mathrm{RMSEA}=.00 ; \mathrm{CFI}=1.00, \mathrm{TLI}=1.030 ; \mathrm{SRMR}=.021)$ with statistically significant associations between the predictor variables, level and growth rate component is displayed in Fig. 2. Model 2 suggests that metacognitive knowledge and



Fig. 2 The latent growth curve Model 2 for narrative picture book comprehension and the predictors (standardized estimates). All paths displayed as solid lines are significant at $p<.05^{*}, p<.01^{* *}$, $p<.001 * * *$ 
task orientation are uniquely contributing to the growth of picture book comprehension from preschool to Grade 3.

\section{Discussion}

In the present study, we examined the development of narrative picture book comprehension among Finnish-speaking children from preschool (age 5) to Grade 3 (age 9). We used wordless picture books and investigated individual differences both in the initial level and the growth of comprehension. We also analyzed the unique contributions of vocabulary, metacognitive knowledge and task orientation to the initial level as well as to the development of narrative picture book comprehension.

Several important findings emerged. First, latent growth curve modeling showed significant variability in the growth of picture book comprehension. In addition, the robust negative association between the initial level and the growth rate of picture book comprehension suggests a pattern of decreasing achievement gaps. The lower the level of picture book comprehension at age 5, the steeper the improvement of it from age 5 to age 9. This developmental pattern is a novel finding. It adds to previous longitudinal studies (Florit, Roch, \& Levorato, 2014; Kendeou et al., 2009; Lepola et al., 2016; Paris \& Paris, 2003), which have not considered individual growth rates in narrative picture book comprehension.

Second, in line with our hypothesis and previous studies (Annevirta et al., 2007; Paris \& Paris, 2003; Silva \& Cain, 2015; Strasser \& del Rio, 2013), both vocabulary and metacognitive knowledge uniquely contributed to the concurrent level of picture book comprehension. The results further showed, partly in contrast to our hypothesis, that metacognitive knowledge was as strongly related to picture book comprehension as vocabulary. Thus, the more the preschoolers could verbally refer to factors influencing memory, understanding and learning, the better they comprehended the narrative conveyed exclusively in pictures.

Third, metacognitive knowledge and task orientation were positive and statistically significant predictors of the growth of picture book comprehension over and above its initial level. Vocabulary at the age of 5 was not related to this development. However, this is not to say that it does not play a role. Rather, the positive correlations in Table 2 for vocabulary suggest that the associations are just not strong enough to yield predictive significance in addition to that of metacognitive knowledge and task orientation.

\section{Contribution to research on narrative comprehension}

Previous studies have shown that metacognitive knowledge is associated with listening and reading comprehension during the early school years (Annevirta et al., 2007; van Kraayenoord \& Schneider, 1999). The present study expands these findings to wordless picture book comprehension among preschoolers and importantly, shows a positive association with the subsequent growth of comprehension. This suggests that children's metacognitive knowledge is associated with the development of their 
ability to construct a coherent mental representation (a situation model) of a pictorial narrative. What is more, metacognitive knowledge as measured here bears a resemblance to theory of mind (i.e., ability to consider one's own and others' mental states such as thoughts and feelings). Indeed, both skills can be viewed as developmentally linked representational abilities (Lockl \& Schneider, 2007; for a review, see Schneider, 2008). This way our findings corroborate studies which have suggested a unique role of kindergartners' and first graders' theory of mind in listening comprehension (for a review, see Cartwright \& Guajardo, 2015; Kim, 2016a; Kim \& Phillips, 2016).

The unique contribution of task orientation to the growth of children's narrative picture book comprehension is consistent with previous findings showing a positive correlation between teacher-rated off-line attention and children's listening comprehension (Kim, 2016a), as well as experimenter-rated on-line attention and picture book comprehension (Strasser \& del Rio 2013). Thus, preschoolers' task orientation that is, their ability to concentrate on the task given by the teacher, independent mastery and positive attitude to challenges, seem to be particularly important in building a situation model of a pictorial narrative. Our finding is also compatible with the study by Lehtinen et al. (1995) among grade 5 students. Namely, Lehtinen and colleagues showed that task-oriented students displayed better discourse comprehension strategies, such as activating their previous knowledge and linking teacher's instruction to phenomena outside school, as compared to students with extrinsic motivational patterns.

By analyzing individual differences in the growth rate of picture book comprehension, our findings also expand the study by Lepola et al. (2016) within the same age range. Our latent growth curve modeling showed that task orientation (measured at age 5) fell short of significance as a concurrent predictor of picture book comprehension although it gained predictive strength in the later comprehension development. A possible explanation is that an average comprehension level of five-yearolds could be achieved by shallow processing, for example, straightforward recall of story details and what was presented in the picture. However, the higher scores typically achieved by older children demanded deep processing which presupposes effort and sustained attention when working out the storyline and integrating information across individual pictures. Interpreted this way, our findings about task orientation are compatible with the studies of the predictive role of executive functions such as planning and ability to focus on task-relevant goals in oral comprehension tasks (Fuhs, Nesbitt, Farran, \& Dong, 2014) and beginning reading comprehension (for a meta-analysis, see Follmer, 2018).

A novel albeit counterintuitive finding was that while vocabulary at the age of five was moderately correlated with picture book comprehension at every time point (see also Silva \& Cain, 2015; Strasser \& del Rio, 2013), it failed to predict the growth rate of comprehension. Sufficient vocabulary is necessary for naming pictures and their elements. However, acquiring a better narrative comprehension is based on more than mere naming and telling. In other words, building a situational model as well as reasoning about it presuppose the active use of world knowledge and prior experiences. It is plausible that such processes are guided by, for example, metacognitive knowledge rather than knowledge of words. This is in line with the 
recent finding by Edossa, Neuenhaus, Artelt, Lingel and Schneider (2019) showing that metacognitive knowledge at grade 5 contributed to positive gains in reading comprehension from Grade 5 to Grade 8 even after controlling of students' verbal ability.

\section{Implications for research and pedagogical practice}

Picture books in which the child must interpret pictures and make connections among the story events, provide a potential tool to study the development of interindividual differences in narrative comprehension in the absence of constraints induced by listening or reading. Reading comprehension difficulties tend to remain unobserved during the first school years for the simple reason that they are overshadowed by problems of decoding accuracy and fluency particularly in opaque orthographies such as English. On the other hand, comprehension difficulties may even occur in the presence of reasonably good word reading skills. The latter situation is aptly depicted by terms such as specific reading comprehension difficulties (e.g., Cain \& Oakhill, 2006; Nation, Cocksey, Taylor, \& Bishop, 2010) and late-emerging poor reading (e.g., Catts et al., 2012).

The present findings contribute to research on late-emerging poor readers (Catts et al., 2012) because by using retelling task, explicit questions as well as implicit ones from preschool to Grade 3 we were able to delineate early individual differences in narrative picture book comprehension and its changes. Such a developmental approach is in several ways useful when identifying poor comprehenders. Previous research suggests that listening comprehension tasks differentiate among four-year-olds whereas picture book comprehension tasks start showing predictive validity one year later (Lepola, 2015). Comprehending wordless picture book does not require active listening, in which domain poor comprehenders often have weaknesses (Catts et al., 2012, Fig. 1), and therefore the growth in comprehension is less confounded by verbal memory. Also, while avoiding possible problems with word reading, the process of picture book comprehension otherwise resembles reading comprehension that is, the child can stop and study the picture in view and also turn back to previous pictures/events. In this way, picture book comprehension provides a less confounded access to processes underlying reading comprehension, thereby giving space to predictors known to be associated with later reading comprehension problems (Guthrie, McRae, \& Klauda, 2007; Vauras, Rauhanummi, Kinnunen, \& Lepola, 1999). In this vein, our modeling showed that task orientation and metacognitive knowledge, previously examined in relation to reading comprehension, are important in narrative picture book comprehension already in preschool. It is plausible that these factors play a role in children's responsiveness to early story comprehension interventions such as those carried out with preschoolers (Bianco et al., 2010) or first graders (Paris \& Paris, 2007).

A promising finding was that the initial inter-individual gap in picture book comprehension showed a significant tendency to decrease over the years and that this positive development was positively associated with the level of task orientation and metacognitive knowledge at the age of five. In other words, the latter two factors 
appear to be resources that facilitate the growth of comprehension. If the present finding about decreasing performance gap is replicable, it suggests that pictorial narratives have a potential detect comprehension skills otherwise not accessible and they could be utilized to fight Matthew effects in reading comprehension. However, a caveat has to be noted. As Fig. 1 suggests, there were students who did not show this pattern. It remains an open question whether this was caused by their low level of task orientation and metacognition or by factors not included in the present study.

As already stated, the precise roles of metacognition and task orientation in picture book comprehension cannot be fully outlined on the basis of the current data. However, it is reasonable to argue that at least facilitation of some type occurs. If this holds true, then the question arises as to how to bring about such a facilitation even earlier, for example, as a collaboration involving parents and early educators working in tandem (e.g., Zevenbergen \& Whitehurst, 2003). Both early educators and parents can enhance children's narrative comprehension skills early on, for instance, by modeling retelling, giving opportunities to respond questions, and teaching children to ask what, why, and how questions. Such activities foster the children's metacognition and inference-making. It is also important that parents and early educators support the children's participation, agency and task-oriented behaviors during shared book reading. This can be achieved by showing responsiveness and giving supportive feedback to children's initiatives and contributions before, during and after story reading (Kajamies, Lepola, \& Mattinen, 2019). Interestingly, wordless picture books have been found to facilitate pre-readers' verbal participation and responsive interaction more than the use of storybooks with text (ChaparroMoreno et al., 2017).

\section{Limitations}

The present study has some important limitations. Firstly, there were only three time points (preschool, kindergarten, Grade 3) to examine individual differences in the growth of picture book comprehension. Thus, we could not evaluate the acceleration or deceleration of picture-book comprehension during the first two school years, a time that is critical for children's responsiveness to reading instruction and to the development of comprehension skills (LARRC, 2017; LARRC \& Yeomans-Maldonado, 2017; Massonnié, Bianco, Laurent \& Bressoux, 2018). Secondly, although only one child scored at maximum in Grade 3 picture book comprehension, this variable was skewed to the left. This means that room for the growth of narrative comprehension was restricted in Grade 3. Thus, caution should be exercised when generalizing the present finding of decreasing achievement gaps in picture book comprehension. Thirdly, we relied on off-line tasks in the assessment of comprehension skills. On-line measures focusing on a child's narrative thinking skills (Tompkins et al., 2013), comprehension monitoring (Kinnunen et al., 1998; Strasser \& del Rio, 2013) and strategic behavior while viewing a picture book may better delineate the growth of narrative comprehension. Finally, we used teacher ratings for children's domain general task-oriented behavior, rather than direct observations. 


\section{Conclusion}

The findings of this four-year-long study suggest that picture book comprehension showed a good diagnostic potential for preschoolers' narrative comprehension in terms of strengths and weaknesses as well as growth. Of note is that using wordless picture books as medium, problems of poor decoding while reading and memory overload while listening can be avoided in diagnostic work. Consequently, the early assessment of children's narrative picture book comprehension gives a fair chance to higher-order comprehension skills such as inference-making which is important in the construction of a coherent mental representation of a narrative. The absence of these cognitive and reading-related stumbling blocks also gives space to facilitative factors not directly related to literacy. In the present study the latter were represented by metacognitive knowledge and task orientation. The present results also lend support to the notion that in such a setting, it becomes possible to detect progress in children's comprehension skills which otherwise might remain in hiding.

Acknowledgements Open access funding provided by University of Turku (UTU) including Turku University Central Hospital. This research was supported by grant (118330) from the Academy of Finland to Janne Lepola. We wish to thank the participating students and the administrators and teachers of the daycare centers and elementary schools where this follow-up study took place. We also thank Ph.D. Julie Lynch (Saginaw Valley State University) for her helpful and constructive comments.

Open Access This article is licensed under a Creative Commons Attribution 4.0 International License, which permits use, sharing, adaptation, distribution and reproduction in any medium or format, as long as you give appropriate credit to the original author(s) and the source, provide a link to the Creative Commons licence, and indicate if changes were made. The images or other third party material in this article are included in the article's Creative Commons licence, unless indicated otherwise in a credit line to the material. If material is not included in the article's Creative Commons licence and your intended use is not permitted by statutory regulation or exceeds the permitted use, you will need to obtain permission directly from the copyright holder. To view a copy of this licence, visit http://creativecommons.org/licen ses/by/4.0/.

\section{Appendix}

\section{An example of the memory task in metacognitive knowledge test: the number of items in remembering objects}

There are 3 boys here, and everyone has been given the task. The task of this boy is to remember 18 objects, (experimenter points picture 1), the task of this boy is to remember 3 objects (experimenter points picture 2), and the task of this boy is to remember 9 objects (experimenter points picture 3 ). Which one of the boys had the most difficult task? 
1

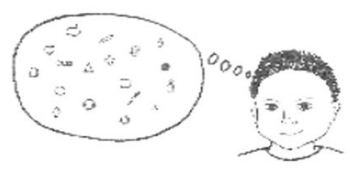

2

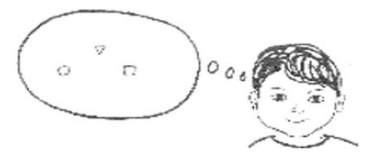

3



After picture selection, the child was asked why was it the most difficult for $\mathrm{x}$ (this boy) to remember all the objects? Explanations were scored on a five-point scale from 0 to 4 .

The child got 0 points if s/he did not point or verbally refer to any out of three pictures. One point was given if the child selected one of the pictures, but her/his explanation for selecting the picture was unclear, naïve or child expressed that s/he don't know: "I don't know" (picture 1); "well, because it cannot remember anymore those tasks (picture 2)"; "that is because because" (picture 1). Two points for less explicit, slight reference to the person's mental processing, for instance by referring to the distinct feature in the selected picture:"because those are so much" (picture 3); "it has more" (picture 1); "that's because it has most" (picture 1). Three points for referring both the distinctive feature in picture and also cognitive processing (memory): "because it has the most of the objects to remember" (picture 1); "because it nearly does not remember all these" (picture 1). Four points for more explicit explanations referring to relevant mental processes (memory): "because so much, and you can't remember so much" (picture 1).

\section{References}

Annevirta, T., Laakkonen, E., Kinnunen, R., \& Vauras, M. (2007). Developmental dynamics of metacognitive knowledge and text comprehension skill in the first primary school years. Metacognition and Learning, 2, 21-39. https://doi.org/10.1007/s11409-007-9005-x.

Annevirta, T., \& Vauras, M. (2001). Metacognitive knowledge in primary grades: A longitudinal study. European Journal of Psychology of Education, 16, 257-282. https://doi.org/10.1007/BF03173029.

Annevirta, T., \& Vauras, M. (2006). Developmental changes of metacognitive skill in elementary school children. Journal of Experimental Education, 74, 197-225. https://doi.org/10.3200/JEXE.74.3.195-226.

Arizpe, E. (2013). Meaning-making from wordless (or nearly wordless) picturebooks: What educational research expects and what readers have to say. Cambridge Journal of Education, 43, 163-176. https ://doi.org/10.1080/0305764X.2013.767879.

Aunola, K., Leskinen, E., Onatsu-Arvilommi, T., \& Nurmi, J.-E. (2002). Three methods for studying developmental change: A case of reading skills and self-concept. British Journal of Educational Psychology, 72, 343-364. https://doi.org/10.1348/000709902320634447.

Bianco, M., Bressoux, P., Doyen, A. L., Lambert, E., Lima, L., Pellenq, C., et al. (2010). Early training of oral comprehension and phonological skills: Results of a 3 year longitudinal study. Scientific Studies of Reading, 14, 211-246. https://doi.org/10.1080/10888430903117518.

Bruner, J. (1986). Actual minds, possible worlds. Cambridge, MA: Harvard University Press.

Cain, C., \& Oakhill, J. (2006). Profiles of children with specific reading comprehension difficulties. British Journal of Educational Psychology, 76, 683-696. https://doi.org/10.1348/000709905X67610.

Cartwright, K. B., \& Guajardo, N. R. (2015). The role of hot and cool executive functions in prereader comprehension. In A. DeBruin-Parecki, A. van Kleeck, \& S. Gear (Eds.), Developing early 
comprehension: Laying the foundation for reading success (pp. 151-177). Baltimore, MD: Paul H. Brookes.

Catts, H. W., Compton, D., Tomblin, J. B., \& Bridges, M. S. (2012). Prevalence and nature of late-emerging poor readers. Journal of Educational Psychology, 105, 166-181. https://doi.org/10.1037/a0025 323.

Chaparro-Moreno, L. J., Reali, F., \& Maldonado-Carreno, C. (2017). Wordless picture books boost preschoolers' language production during shared reading. Early Childhood Research Quarterly, 40, 52-62. https://doi.org/10.1016/j.ecresq.2017.03.001.

Conners, F. A. (2009). Attentional control and the simple view of reading. Reading and Writing: An Interdisciplinary Journal, 22, 591-613. https://doi.org/10.1007/s11145-008-9126-X.

Diener, C. I., \& Dweck, C. S. (1978). An analysis of learned helplessness: Continuous changes in performance, strategy, and achievement cognitions following failure. Journal of Personality and Social Psychology, 36, 451-462. https://doi.org/10.1037/0022-3514.36.5.451.

Dufva, M., Niemi, P., \& Voeten, M. J. M. (2001). The role of phonological memory, word recognition, and comprehension skills in reading development: From preschool to grade 2. Reading and Writing: An Interdisciplinary Journal, 14, 91-117. https://doi.org/10.1023/A:1008186801932.

Edossa, A. K., Neuenhaus, N., Artelt, C., Lingel, K., \& Schneider, W. (2019). Developmental relationship between declarative metacognitive knowledge and reading comprehension during secondary school. European Journal of Psychology of Education, 34, 397-416. https://doi.org/10.1007/s1021 2-018-0393-X.

Feldman, C. F., Bruner, J., Renderer, B., \& Spitzer, S. (1990). Narrative comprehension. In B. K. Briton $\&$ A. D. Pellegrini (Eds.), Narrative thought and narrative language (pp. 1-78). Hillsdale, NJ: Lawrence Erlbaum.

Filiatrault-Veilleux, P., Bouchard, C., Trudeau, N., \& Desmaraisd, C. (2016). Comprehension of inferences in a narrative in 3- to 6-year-old children. Journal of Speech, Language, and Hearing Research, 59, 1099-1110. https://doi.org/10.1044/2016_JSLHR-L-15-0252.

Flavell, J. H. (1979). Metacognition and cognitive monitoring: A new area of cognitive developmental inquiry. American Psychologist, 34, 906-911.

Florit, E., Roch, M., Altoé, G., \& Levorato, M. C. (2009). Listening comprehension in preschoolers: The role of memory. The British Journal of Developmental Psychology, 27, 935-951. https://doi. org/10.1348/026151008X397189.

Florit, E., Roch, M., \& Levorato, M. C. (2011). Listening text comprehension of explicit and implicit information in preschoolers: The role of verbal and inferential skills. Discourse Processes, 48, 119138. https://doi.org/10.1080/0163853X.2010.494244.

Florit, E., Roch, M., \& Levorato, M. C. (2014). Listening text comprehension in preschoolers: A longitudinal study on the role of semantic components. Reading and Writing: An Interdisciplinary Journal, 27, 793-817. https://doi.org/10.1007/s11145-013-9464-1.

Follmer, J. (2018). Executive function and reading comprehension: A meta-analytic review. Educational Psychologist, 53, 42-60. https://doi.org/10.1080/00461520.2017.1309295.

Fuhs, M., Nesbitt, K., Farran, D., \& Dong, N. (2014). Longitudinal associations between executive functioning and academic skills across content areas. Developmental Psychology, 50, 1698-1709. https ://doi.org/10.1037/a0036633.

Georgiou, G., Manolitsis, G., Zhang, X., Parrila, R., \& Nurmi, J.-E. (2013). Examining the developmental dynamics between achievement strategies and different literacy skills. International Journal of Behavioral Development, 37, 173-181. https://doi.org/10.1177/0165025413477007.

Guthrie, J. T., McRae, A., \& Klauda, S. L. (2007). Contributions of concept-oriented reading instruction to knowledge about interventions for motivations in reading. Educational Psychologist, 42, 237-250.

Harter, S. (1981). A new self-report scale of intrinsic versus extrinsic orientation in the classroom: Motivational and informational components. Developmental Psychology, 17, 300-312. https://doi. org/10.1037//0012-1649.17.3.300.

Hirvonen, R., Georgiou, G. K., Lerkkanen, M.-K., Aunola, K., \& Nurmi, J.-E. (2010). Task-focused behaviour and literacy development: A reciprocal relationship. Journal of Research in Reading, 33, 302-319. https://doi.org/10.1111/j.1467-9817.2009.01415.x.

Kajamies, A., Lepola, J., \& Mattinen, A. (2019). Scaffolding children's narrative comprehension skills in early education and home settings. In K. J. Kerry-Moran \& J. A. Aerila (Eds.), Story in children's lives: Contributions of the narrative mode to early childhood development, literacy, and learning (pp. 153-173). Cham: Springer. 
Kendeou, P., Bohn-Gettler, C., White, M. J., \& van den Broek, P. (2008). Children's inference generation across different media. Journal of Research in Reading, 31, 259-272. https://doi.org/10.111 1/j.1467-9817.2008.00370.x.

Kendeou, P., van den Broek, P., White, M. J., \& Lynch, J. (2009). Predicting reading comprehension in early elementary school: The independent contributions of oral language and decoding skills. Journal of Educational Psychology, 101, 765-778. https://doi.org/10.1037/a0015956.

Khan, K. S., Gugiu, M. R., Justice, L. M., Bowles, R. P., Skibbe, L. E., \& Piasta, S. B. (2016). Agerelated progressions in story structure in young children's narratives. Journal of Speech, Language, and Hearing Research, 59, 1395-1408. https://doi.org/10.1044/2016_JSLHR-L-15-0275.

Kim, Y.-S. G. (2016a). Direct and mediated effects of language and cognitive skills on comprehension of oral narrative texts (listening comprehension) for children. Journal of Experimental Child Psychology, 141, 101-120. https://doi.org/10.1016/j.jecp.2015.08.003.

Kim, Y.-S. G. (2016b). Do live versus audio-recorded narrative stimuli influence young children's narrative comprehension and retell quality? Language, Speech, and Hearing Services in Schools, 47, 77-86. https://doi.org/10.1044/2015_LSHSS-15-0027.

Kim, Y.-S. G., \& Phillips, B. (2016). Five minutes a day to improve comprehension monitoring in oral language contexts: An exploratory intervention study with prekindergartners from low-income families. Topics in Language Disorders, 36, 356-367. https://doi.org/10.1097/TLD.0000000000000103.

Kinnunen, R., Vauras, M., \& Niemi, P. (1998). Comprehension monitoring in beginning readers. Scientific Studies of Reading, 2, 353-375. https://doi.org/10.1207/s1532799xssr0204_4.

Kintsch, W., \& Rawson, K. A. (2005). Comprehension. In M. J. Snowling \& C. Hulme (Eds.), The science of reading: A handbook (pp. 209-226). Oxford, UK: Blackwell.

Krahn, F. (1979). Robot-bot-bot. New York, NY: Dutton.

Language and Reading Research Consortium (LARRC). (2017). Oral language and listening comprehension: Same or different constructs? Journal of Speech, Language, and Hearing Research, 60, 1273-1284. https://doi.org/10.1044/2017_JSLHR-L-16-0039.

LARRC, \& Yeomans-Maldonado, G. (2017). Development of comprehension monitoring in beginner readers. Reading and Writing: An Interdisciplinary Journal, 30, 2039-2067. https://doi.org/10.1007/ s11145-017-9765-x.

Lazarus, R. (1991). Emotion and adaptation. Oxford, UK: Oxford University Press.

Lehtinen, E., Vauras, M., Salonen, P., Olkinuora, E., \& Kinnunen, R. (1995). Long-term development of learning activity: Motivational, cognitive, and social interaction. Educational Psychologist, 30, 21-35. https://doi.org/10.1207/s15326985ep3001_3.

Lepola, J. (2015). Heikkojen ja hyvien luetun ymmärtäjien kertomuksen ymmärtämisen taidot, lukemisvalmiudet ja motivaatio 4-9 vuoden iässä [Narrative comprehension skills, prereading skills and motivational orientations from age 4 to age 9 among children with poor and good reading comprehension in grade 3]. Oppimisen ja oppimisvaikeuksien erityislehti NMI-Bulletin, 25, 4-24.

Lepola, J., Lynch, J., Kiuru, N., Laakkonen, E., \& Niemi, P. (2016). Early oral language comprehension, task orientation, and foundational reading skills as predictors of grade 3 reading comprehension. Reading Research Quarterly, 51, 373-390. https://doi.org/10.1002/rrq.145.

Lepola, J., Lynch, J., Laakkonen, E., Silven, M., \& Niemi, P. (2012). The role of inference making and other language skills in the development of narrative listening comprehension in 4-6-year-old children. Reading Research Quarterly, 47, 259-282. https://doi.org/10.1002/RRQ.020.

Leppänen, U., Aunola, K., Niemi, P., \& Nurmi, J.-E. (2008). Letter knowledge predicts grade 4 reading fluency and reading comprehension. Learning and Instruction, 18, 548-564. https://doi. org/10.1016/j.learninstruc.2007.11.004.

Lockl, K., \& Schneider, W. (2007). Knowledge about the mind: Links between theory of mind and later metamemory. Child Development, 78, 148-167. https://doi.org/10.1111/j.1467-8624.2007.00990.x.

Lynch, J. S., van den Broek, P., Kremer, K. E., Kendeou, P., White, M. J., \& Lorch, E. P. (2008). The development of narrative comprehension and its relation to other reading skills. Reading Psychology, 29, 327-365. https://doi.org/10.1080/02702710802165416.

Mandler, J. M., \& Johnson, N. S. (1977). Remembrance of things parsed: Story structure and recall. Cognitive Psychology, 9, 111-151. https://doi.org/10.1016/0010-0285(77)90006-.

Manolitsis, G., Georgiou, G., Stephenson, K., \& Parrila, R. (2009). Beginning to read across languages varying in orthographic consistency: Comparing the effects of non-cognitive and cognitive predictors. Learning and Instruction, 19, 466-480. https://doi.org/10.1016/j.learninstruc.2008.07.003. 
Marulis, L. M., Baker, S. T., \& Whitebread, D. (2020). Integrating metacognition and executive function to enhance young children's perception of and agency in their learning. Early Childhood Research Quarterly, 50, 46-54. https://doi.org/10.1016/j.ecresq.2018.12.017.

Marulis, L. M., Palincsar, A. S., Berhenke, A. L., \& Whitebread, D. (2016). Assessing metacognitive knowledge in 3-5 year olds: The development of a metacognitive knowledge interview (McKI). Metacognition and Learning, 11, 339-368. https://doi.org/10.1007/s11409-016-9157-7.

Massonnié, J., Bianco, M., Laurent, L., \& Bressoux, P. (2018). Longitudinal predictors of reading comprehension in French at first grade: Unpacking the oral comprehension component of the simple view. Learning and Instruction, 60, 166-179. https://doi.org/10.1016/j.learninstruc.2018.01.005.

Mayer, M. (1967). A boy, a dog and a frog. New York, NY: Dial.

Morgan, P. L., \& Fuchs, D. (2007). Is there a bidirectional relationship between children's reading skills and reading motivation? Exceptional Children, 73, 165-183. https://doi.org/10.1177/0014402907 07300203.

Muthén, B. O., \& Khoo, S.-T. (1998). Longitudinal studies of achievement growth using latent variable modeling. Learning and Individual Differences, 10, 73-101. https://doi.org/10.1016/S1041 -6080(99)80135-6.

Muthén, L. K., \& Muthén, B. O. (1998-2012). Mplus user's guide: Statistical analysis with latent variables (7th ed.). Los Angeles, CA: Muthén \& Muthén.

Nation, K., Cocksey, J., Taylor, J. S. H., \& Bishop, D. V. M. (2010). A longitudinal investigation of early reading and language skills in children with poor reading comprehension. Journal of Child Psychology and Psychiatry, 51, 1031-1039. https://doi.org/10.1111/j.1469-7610.2010.02254.x.

Oakhill, J. V., \& Cain, K. (2012). The precursors of reading ability in young readers: Evidence from a four-year longitudinal study. Scientific Studies of Reading, 16, 91-121. https://doi. org/10.1080/10888438.2010.529219.

Paris, A. H., \& Paris, S. G. (2003). Assessing narrative comprehension in young children. Reading Research Quarterly, 38, 36-76. https://doi.org/10.1598/RRQ.38.1.3.

Paris, A. H., \& Paris, S. G. (2007). Teaching narrative comprehension strategies to first graders. Cognition and Instruction, 25, 1-44. https://doi.org/10.1080/07370000709336701.

Perfetti, C. A., Landi, N., \& Oakhill, J. (2005). The acquisition of reading comprehension skill. In M. J. Snowling \& C. Hulme (Eds.), The science of reading: A handbook (pp. 227-247). Oxford, UK: Blackwell.

Perfetti, C. A., \& Stafura, J. (2014). Word knowledge in a theory of reading comprehension. Scientific Studies of Reading, 18, 22-37. https://doi.org/10.1080/10888438.2013.827687.

Pfost, M., Hattie, J., Dörfler, T., \& Artelt, C. (2014). Individual differences in reading development: Review of 25 years of empirical research on Matthew effects in reading. Review of Educational Research, 84, 203-244. https://doi.org/10.3102/0034654313509492.

Potocki, A., Magnan, A., \& Ecalle, J. (2013). Narrative comprehension skills in 5-year-old children: Correlational analysis and comprehender profiles. The Journal of Educational Research, 106, 14-26. https://doi.org/10.1080/00220671.2012.667013.

Pressley, M., \& Gaskins, I. W. (2006). Metacognitively competent reading comprehension is constructively responsive reading: How can such reading be developed in students? Metacognition and Learning, 1, 99-113. https://doi.org/10.1007/s11409-006-7263-7.

Salonen, P., Lepola, J., Vauras, M., Rauhanummi, T., Lehtinen, E., \& Kinnunen, R. (1994). Diagnostiset testit 3. Motivaatio, metakognitio ja matematiikka [Diagnostic tests 3. Motivation, metacognition and mathematics]. University of Turku, Finland: Centre for Learning Research.

Schneider, W. (2008). The development of metacognitive knowledge in children and adolescents: Major trends and implications for education. Mind, Brain, and Education, 2, 114-121. https://doi. org/10.1111/j.1751-228X.2008.00041.x.

Sesma, H. W., Mahone, E. M., Levine, T., Eason, S. H., \& Cutting, L. E. (2009). The contribution of executive skills to reading comprehension. Child Neuropsychology, 15, 232-246. https://doi. org/10.1080/09297040802220029.

Silva, M., \& Cain, K. (2015). The relations between lower and higher level comprehension skills and their role in prediction of early reading comprehension. Journal of Educational Psychology, 107, 321-331. https://doi.org/10.1037/a0037769.

Silva, M., Strasser, K., \& Cain, K. (2014). Early narrative skills in Chilean preschool: Questions scaffold the production of coherent narratives. Early Childhood Research Quarterly, 29, 205-213. https:// doi.org/10.1016/j.ecresq.2014.02.002.

Statistics Finland. (2007). Statistical yearbook of Finland 2007. Helsinki: Multiprint. 
Storch, S. A., \& Whitehurst, G. J. (2002). Oral language and code-related precursors to reading: Evidence from a longitudinal structural model. Developmental Psychology, 38, 934-947. https://doi. org/10.1037/0012-1649.38.6.934.

Strasser, K., \& del Rio, F. (2013). The role of comprehension monitoring, theory of mind, and vocabulary depth in predicting story comprehension and recall of kindergarten children. Reading Research Quarterly, 49, 169-187. https://doi.org/10.1002/rrq.68.

Tompkins, V., Guo, Y., \& Justice, L. M. (2013). Inference generation, story comprehension, and language skills in the preschool years. Reading and Writing: An Interdisciplinary Journal, 26(3), 403-429. https://doi.org/10.1007/s11145-012-9374-7.

Torppa, M., Georgiou, G. K., Lerkkanen, M.-K., Niemi, P., Poikkeus, A.-M., \& Nurmi, J.-E. (2016). Examining the simple view of reading in a transparent orthography: A longitudinal study from kindergarten to grade 3. Merrill-Palmer Quarterly, 62, 179-206.

van Kraayenoord, C. E., Beinicke, A., Schlagmuller, M., \& Schneider, W. (2012). Word identification, metacognitive knowledge, motivation and reading comprehension: An Australian study of Grade 3 and 4 pupils. Australian Journal of Language and Literacy, 35, 51-68.

van Kraayenoord, C. E., \& Schneider, W. (1999). Reading achievement, metacognition, reading self-concept and interest: A study of German students in grades 3 and 4. European Journal of Psychology of Education, 14, 305-324.

Vauras, M., Rauhanummi, T., Kinnunen, R., \& Lepola, J. (1999). Motivational vulnerability as a challenge for educational interventions. International Journal of Educational Research, 31, 515-531. https://doi.org/10.1016/S0883-0355(99)00019-1.

Verhoeven, L., \& Perfetti, C. (2008). Advances in text comprehension: Model, process and development. Applied Cognitive Psychology, 22, 293-301. https://doi.org/10.1002/acp.1417.

Viljaranta, J., Lazarides, R., Aunola, K., Räikkönen, E., \& Nurmi, J.-E. (2015). The different role of mothers' and fathers' beliefs in the development of adolescents' mathematics and literacy task values. International Journal of Gender, Science and Technology, 7, 297-317.

Wang, J., \& Wang, X. (2012). Structural equation modeling: Applications using Mplus. West Sussex, UK: Higher Education Press.

Wechsler, D. (1999). WISC-III: Wechslerin lasten älykkyystestistö [Wechsler Intelligence Scale for Children, third edition]. Helsinki, Finland: Psykologien Kustannus.

Wellman, H. M. (1977). Preschoolers' understanding of memory relevant variables. Child Development, 48, 1720-1723.

Zevenbergen, A., \& Whitehurst, G. J. (2003). Dialogic reading: A shared picture book reading intervention for preschoolers. In A. van Kleeck, S. A. Stahl, \& E. B. Bauer (Eds.), On reading books to children: Parents and teachers (pp. 177-200). Mahwah, NJ: Lawrence Erlbaum.

Publisher's Note Springer Nature remains neutral with regard to jurisdictional claims in published maps and institutional affiliations. 